\title{
Current Situation and Reform Thought of Experimental Teaching of Financial Specialty under the Background of Big Data
}

\author{
Ge Meilian \\ Taishan University, Taishan Tanan, 271000, China
}

\begin{abstract}
With the rapid development of information technology in China, the application of big data technology is more and more extensive. Under the background of big data era, combined with the basic situation of experimental teaching in the process of training financial professionals in colleges and universities in China, this paper analyzes its disadvantages, gives the right remedy, and puts forward the training method which can improve the financial professionals accurately.
\end{abstract}

Keywords: big data; finance major; experimental teaching

Under the background of economic globalization, the development of financial industry in China has been accelerated, and the demand for financial talents is increasing day by day. In addition to the basic and steady theoretical knowledge, the quality of modern financial talents must also have the ability of big data thinking and analysis. Therefore, experimental teaching, as a method that can connect theoretical knowledge with practical application, must attract the attention of colleges and universities. In practice, financial students can also improve their ability to adapt and innovate, and their understanding of professional ethics in the financial industry will also climb another high building.

I. Current Situation of Experimental Teaching of Financial Specialty in Colleges and Universities

https://doi.org/10.47852/bonviewCETR2020010223

This is an open access article published by the BON VIEW PUBLISHING PTE. under the Creative Commons Attributions License. 
A. The curriculum is rigid and old

The purpose of financial specialty is to provide high-quality talents for the national financial industry. However, in the courses offered in colleges and universities, macro theory occupies a dominant position, and the amount of practical teaching is less. In the only practical teaching, the content of practical teaching lags behind, and the knowledge of traditional banking, insurance and securities is more involved. For example, the commercial bank comprehensive business training, securities foreign exchange futures simulation and other experiments, are banks, securities and other basic knowledge of the verification experiment. Such courses can not keep pace with the times.

B. Insufficient experimental teaching equipment and utilization

The hardware and software of experimental teaching are the basis of the smooth development of experimental teaching. For this aspect, there are still many problems in colleges and universities.

With the continuous development of the times, the requirements for all aspects of experimental teaching are becoming higher and higher for finance majors. The demand for independent financial professional laboratories is more urgent, but at present, because universities emphasize theory and experiment teaching mode, most colleges and universities do not have special laboratories. Most of the ways in which students receive knowledge are teachers' indoctrination teaching, which is not only inefficient, but also reduces students' enthusiasm for learning and lacks practical teaching. Students' innovation can not be brought into play, which can easily lead to the problems of block thinking, old views and so on, and it is difficult to adapt to the changing financial market.

C. Lack of teachers

As students, $80 \%$ of knowledge may come from teachers. But both theoretical and practical teachers are scarce. At present, there are many teachers with theoretical knowledge and high theoretical knowledge, but most of these teachers have to undertake practical teaching. For many teachers, practical teaching is not easy.

D. Uncoordinated curriculum arrangement between theory and practice

The type of practical courses is single, most of them are some confirmatory experiments on basic theoretical courses. The content of experimental technology is low, which is suitable for students' basic understanding of the industry, but it can not improve the students. Experimental teaching should complement the theoretical teaching, lack of comprehensive experimental teaching, students may be difficult to have a deeper understanding of theoretical knowledge. 


\section{Financial industry in the big data era}

The concept of big data is very abstract, it has many attributes, such as high dimension, complexity, strong noise, low value density, social attribute and so on. With the development of big data, the social attribute of big data is revealed step by step. Now, big data opportunities are applied to all aspects of our life. The most basic and core advantage of big data is that it processes large and complicated data and presents them clearly in front of the demanders. For the financial industry, such an information industry, big data should greatly improve the efficiency of work. The financial industry follows the pace of the big data era and continuously improves the informatization of the financial industry. Combined with the data collection, machine learning, data modeling and other methods of big data technology, the intuitive data are applied to all aspects of the financial industry. Has the data collection, the information asset statistics and so on aspect convenience.

\section{A. Innovative financial operations}

In the era of information explosion, what matters is not information, but useful information. The amount of data in the financial industry itself is very large. If we only rely on traditional computing technology, it takes a lot of energy to process these data.

Big data technology has the ability to process the information meticulously. It provides easy analysis and high efficiency data for data collection and information asset statistics. Comprehensive information is clearly divided, and some potential data are deeply mined, which promotes the innovation and development of the whole financial business.

Moreover, because the information of big data analysis is more intuitive and multi-level. In other words, we can say that the information of big data analysis is more targeted. Not empty numbers, we can accurately locate user needs through different levels of data, which is a new and efficient way of financial services.

\section{B. Reducing financial risk}

All kinds of business in the financial field, generally accompanied by a large number of currency circulation activities, business data will be generated accordingly. Therefore, the prevention of financial risk is a part of the financial industry.

The perfection of China's credit system has promoted the development of the financial industry. Traditional financial risk management has been unable to adapt to market demand. The data mining technology of big data technology is the product of combining the application of statistical theory, intelligent technology and database technology.This process can be simply summarized into three steps: 
preparing data, mining data, and analyzing data. With the help of mining technology, manufacturers can analyze and discover the risk information related to the development of the industry and the personal credit information of users, so as to predict the risk level and provide reference data for decisionmaking. This internal data analysis ability greatly improves the security of financial business and reduces the risk.

At the same time, the financial industry often faces economic crimes, including money laundering, malicious overdraft, forgery of credit cards and other acts. Big data technology integrates multiple database information and combines analysis tools to detect abnormal data. Analyze and summarize all kinds of information, identify and summarize the important connections and patterns of activities, which can provide clues for personnel.

C. Strengthening financial supervision

Big data all-round, multi-faceted information model for the financial industry to provide more scientific decision-making basis. The guiding data of local monitoring apply the regional financial data in big data technology, clear and intuitive multi-regional financial index, real-time dynamic analysis, which is conducive to timely and accurate financial supervision decisions. To the healthy development of the financial industry has made outstanding contributions.

\section{Reform of Experimental Teaching of Financial Specialty under the Background of Big Data}

The times are constantly improving, college students shoulder the future of the motherland, they need to keep pace with the times, have the ability to adapt to the times.

A. Cultivation of professional ethics

No matter any profession, the cultivation of professional ethics is basic and most important. The so-called adult before virtue.

For the financial industry, professional ethics is particularly important. Under the influence of the global economy, China's economy and financial industry are developing relatively fast, international trade activities are frequently exchanged, and a large number of financial talents need to be introduced. International trade exchange is also a part of the national image. For college students, vocational education should focus on strengthening students' sense of professional mission and responsibility, and standardize students' thoughts and behaviors according to the requirements of the financial industry. Professional ethics is embodied in all aspects of practical teaching. Teaching teachers should also shoulder their responsibilities, set up correct values and set a good example. Training activities can be carried out properly to improve students' psychological quality and comprehensive accomplishment in 
practice.

B. Setting reasonable financial teaching objectives

With the development of big data has been deeply applied, the needs of the financial industry will be adjusted and modified. Teachers need to closely combine the development of the times, using big data analysis to understand the current financial needs. Train the lack of talent in the financial industry.

Experimental teaching of finance major is a very practical subject. In the process of teaching, we need to highlight its practicality and application. According to the current situation of talent orientation in financial industry, students need to master the corresponding practical ability.

C. Optimizing the experimental curriculum system and teaching methods

At present, the practical teaching of financial specialty, such as experiment and practical training, basically revolves around the traditional financial knowledge. In the present society, the practical value is not high. The old and monotonous practice teaching society makes students produce solidified thinking, which is not conducive to the handling of field events in the future. This requires that the financial practice courses in colleges and universities should be combined with the current development of the financial industry, and optimize and innovate the experimental curriculum system and experimental contents of the financial specialty to lay the foundation for the students' knowledge application ability.

To understand and master the traditional basic knowledge of finance, however, as a strong applied major, finance specialty must combine the characteristics of the demand for financial professionals in the big data era. To strengthen the weight of practical teaching in the course, the systematic planning and management practice teaching should be progressive layer by layer. After the students have mastered the basic knowledge, the corresponding practical teaching should be formulated according to the arrangement of the theoretical course. from simulation, simulation, synthesis and other aspects of optimization to break the traditional confirmatory experimental model. At the same time, we should strengthen the experimental items of comprehensive experiment and research experiment, so that students can have a deeper understanding of financial knowledge and big data theory in the course of the experiment.In the era of big data, the penetration of big data to the industry is very high. After graduation, students will come into contact with big data, and cultivate students' understanding and analysis ability of big data in advance, which will pave the way for the future. Practice teaching should pay attention to infiltrating data thinking in the process, students' mastering data thinking can improve students' ability of financial data analysis.

D. Resources and equipment for teachers and development 
Laboratories are material products that can be built for students in a short period of time as long as sufficient funds are invested. But teacher resources are honed by time and experience. Schools can regularly hold big data technology and finance related courses for teachers, urge teachers to keep pace with the times, add assessment system and improve efficiency.

After mastering more knowledge of big data, teachers can design relevant courses more easily. At the same time, they should also establish a quality evaluation system to evaluate students' practical teaching results.

\section{Conclusion}

The arrival of the big data era has brought changes and opportunities to many industries. The industry needs to keep pace with the times, and so do the talents in the industry. The financial industry needs applied talents. In the courses offered in colleges and universities, we should pay attention to the quality of practical teaching, at the same time, combine with the development of the times, help students to establish big data thinking, train talents who meet the needs of society, and cultivate the pillars of our country's economic development.

\section{Acknowledgement}

This work is supported in part by The twelfth batch of teaching reform projects of Taishan College: a study on the construction of finance curriculum system and the reform of teaching mode based on “Internet”(No:201917)

\section{References}

[1] Zhao Zhouhua. Current Situation and Reform Ideas of Experimental Teaching of Financial Specialty under the J]. of Big Data Journal of Liaoning Institute of Education Administration ,2019,36(05):66-70.

[2] early dawn. Big Data's Impact on the Financial Industry [J].]; and China Business Theory 2020(22):40-41.

[3] Li Shaokun. Innovation [J].] of Financial Experiment Teaching Mode Journal of Shandong Institute of Administration, Shandong Institute of Economic Management cadres ,2006(S1):109-110. 